\title{
Ghanges in composition of the digesta along the alimentary tract of sheep
}

\author{
By A. W. BOYNE, ROSA M. CAMPBELL, J. DAVIDSON \\ AND D. P. CUTHBERTSON \\ Rowett Research Institute, Bucksburn, Aberdeenshire \\ (Received 30 April 1956)
}

Because of the complexity of the interactions involved very few attempts have been made to trace the fate of ingested food in the course of its digestion and absorption along the alimentary tract of the ruminant. Elsden, Hitchcock, Marshall \& Phillipson (1946) made a comparative study of the weights of the digesta and their dry-matter and volatile fatty-acid content in the consecutive parts of the alimentary tract of four sheep. By means of a lignin-ratio method Hale, Duncan \& Huffman (1947a, b) showed that maximum digestion in the bovine rumen was obtained within $\mathrm{i} 2 \mathrm{~h}$ after feeding and tended to come to a standstill thereafter. They found that during the first $6 \mathrm{~h}$ the predominant phenomenon was the rapid disappearance from the rumen of the more soluble nutrients. During the next $6 \mathrm{~h}$ after feeding, cellulose was rapidly disintegrated. Under the conditions of their experiment an average of $\mathrm{I} \cdot \mathrm{r} \%$ cellulose and $9.5 \%$ protein was later released from the food residues in their further passage along the tract. No observations were made on the fate of the digesta in the other parts of the tract. When, therefore, an experiment of one of our colleagues made a number of ewes available we investigated changes in the quantity and composition of the digesta along the alimentary tract, and also changes in each part of the tract with time after feeding. The concentrations of dry matter (D.M.), ash, nitrogen, energy and volatile fatty acids (V.F.A.) were estimated. Such information is fundamental to a more dynamic appraisal of the processes of digestion and absorption.

\section{EXPERIMENTAL}

Twenty-four 5-year-old Cheviot ewes which had lambed in spring, 1951, and weighed about $5^{8} \mathrm{~kg}$, were housed in pens and fed on a diet varying in limestone content because they were on an experiment to define calcium requirement for pregnancy and lactation. They were given water $a d l i b$. and the diet was (g/day):

Hay
Ground maize
Decorticated extracted groundnut meal
Dried yeast
$\mathrm{Na}_{2} \mathrm{H} \mathrm{PO}_{4} \cdot \mathrm{I}_{2} \mathrm{H}_{2} \mathrm{O}$
$\mathrm{NaCl}$
Ground limestone
$\quad$ Total

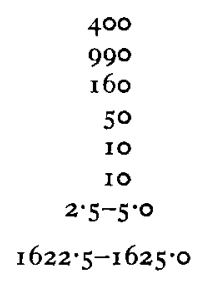


The food fed daily to each sheep had the following composition:

\begin{tabular}{|c|c|c|c|}
\hline $\begin{array}{l}\text { D.M. } \\
\text { (g) }\end{array}$ & $\begin{array}{c}\text { Ash } \\
\text { (g) }\end{array}$ & $\begin{array}{l}\mathrm{N} \\
\text { (g) }\end{array}$ & $\begin{array}{l}\text { Gross calories } \\
\text { (Cal.) }\end{array}$ \\
\hline 1300 & About 60 & 34 & 5600 \\
\hline
\end{tabular}

The range of limestone values was negligible compared with the total dry matter of the diet and was only about $4 \%$ of the total ash content.

The ewes were trained to eat their food in two equal lots, fed at 8 a.m. and 8 p.m. daily. Residues, if any, were removed at 9 a.m. and 9 p.m. and then weighed. The ewes were killed during the late summer $195^{\mathrm{I}}$, in such a fashion that the alimentary tract and its contents from one ewe were available for analysis on the morning of each full working day. The ewes were killed at $2,4,6,8$, Io or $\mathrm{i} 2 \mathrm{~h}$ after the presentation of the morning or evening meals and the times of killing, as well as the sheep to be killed, were randomized among the calendar dates. Irregularities in eating habits existed among three ewes and the results for these were discarded.

Each ewe was killed with a humane killer, and the abdominal cavity was quickly opened. With the minimum of disturbance ligatures were tied on the oesophagus at its junction with the rumen and reticulum, and between the following contiguous parts: reticulo-rumen and omasum, omasum and abomasum, abomasum and small intestine (just distal to the pyloric sphincter), small intestine and caecum; and also at the sharp angle of the colon before its spiral, and at the beginning of the rectum. In two animals ligatures were tied on the small intestine to separate it into two parts. Owing to the variable content of the rectum at any given time it was not examined.

When the tract was removed it was placed in a bucket which was covered with a damp cloth to prevent drying. When ewes were killed at 8 and ro a.m. the tract contents were removed immediately, otherwise the various portions of tract were stored in a cold room at $\mathrm{I}^{\circ}$ until they could be dealt with, generally within $\mathrm{I} 2 \mathrm{~h}$. After removal of obvious fat and adherent tissue the separate parts were weighed. The contents were next removed and transferred to suitable tared containers. From the small intestine the contents were expelled by light digital pressure. The empty parts were rinsed out with normal saline, lightly pressed between filter-paper, and reweighed, in order to give by difference the weight of the contents of each part.

In a second, subsidiary, experiment six sheep on a similar feeding régime were killed $4-8 \mathrm{~h}$ after feeding, and the contents of the abomasum and small intestine were examined. The small intestine was divided into four approximately equal lengths. From two of these the contents were washed out, from the other two they were expressed by digital pressure as in the main experiment. In this subsidiary experiment, insoluble ash was used as a marker.

\section{Chemical methods}

When sampling the wet material care was always taken to ensure thorough mixing. The contents of the colon, for instance, were mixed with a known volume of water in a blender. 
Nitrogen. The macro-Kjeldahl method was used on the wet material.

Volatile fatty acids. These were measured by the method used by Elsden $e t$ al. (1946) on muslin filtrates. On account of continued fermentation during storage at $\mathrm{I}^{\circ}$ the estimates for V.F.A. represent only approximately the amounts present at the time of killing.

Dry matter. Weighed samples were dried in aluminium trays at $60-70^{\circ}$ then in the oven at $105^{\circ}$ to constant weight.

Energy value. Bomb calorimetry was done on dried material.

Ash. Weighed quantities were ashed at $500-600^{\circ}$ in Vitreosil basins.

Insoluble ash. The method described in Fertilizer and Feeding Stuffs Regulations (Minister of Agriculture and Fisheries and Department of Agriculture for Scotland, 1932) was used.

\section{RESULTS}

\section{Changes with time}

For each segment of the tract scatter diagrams were drawn with each of the measurements made plotted against time after feeding. There was no evidence from any of these thirty-six scatter diagrams that the pattern of change with time differed between the sheep killed after the $8 \mathrm{a} . \mathrm{m}$. meal and those killed after the $8 \mathrm{p} . \mathrm{m}$. meal. The results for the two sets were, therefore, combined and the main findings are given in Fig. $\mathrm{I}$ and Table $\mathrm{I}$.

Table I. Mean values and standard deviations for empty weight of parts of the alimentary tract of twenty-one sheep, and their contents in terms of dry matter, ash, total nitrogen, energy, and volatile fatty acids

\begin{tabular}{|c|c|c|c|c|c|c|c|}
\hline Site & $\begin{array}{c}\text { Organ } \\
\text { weight } \\
\text { (g) }\end{array}$ & $\begin{array}{l}\text { Weight } \\
\text { of } \\
\text { contents } \\
\text { (g) }\end{array}$ & $\begin{array}{l}\text { Dry } \\
\text { matter } \\
(\%)\end{array}$ & $\begin{array}{l}\text { Ash } \\
(\%)\end{array}$ & $\begin{array}{l}\text { Total } \\
\text { nitrogen } \\
(\%)\end{array}$ & $\begin{array}{c}\text { Energy } \\
\text { (Cal./ } \\
\text { I00 g } \\
\text { contents) }\end{array}$ & $\begin{array}{l}\text { Volatile fatty } \\
\text { acids } \\
\text { (m-equiv./ } \\
\text { roo g } \\
\text { contents) }\end{array}$ \\
\hline $\begin{array}{l}\text { Reticulo- } \\
\text { rumen }\end{array}$ & Y $160 \pm 200$ & $775^{*} \pm 1930$ & $14.2^{*} \pm 2.6$ & $I \cdot I I^{*} \pm 0 \cdot 13$ & $0.41^{*} \pm 0.13$ & $66^{*} \pm 14$ & $\mathrm{II} \cdot 4^{*} \pm 3 \cdot 0$ \\
\hline Omasum & $187 \pm 56$ & $171 \pm$ & $21 \cdot 9^{*} \pm 2 \cdot 7$ & $\mathrm{I} \cdot 55^{*}$ & $0.77^{*} \pm 0.13$ & $105^{*} \pm 13$ & $7 \cdot 6^{*} \pm \mathrm{I} \cdot 9$ \\
\hline lasum & $3 \pm 69$ & $910^{*} \pm 488$ & $12.7 \pm 2.0$ & $\mathrm{I} .84 \pm 0.78$ & $0.35 \pm 0.05$ & $53 \pm 7$ & $0.64^{*} \pm 0.35$ \\
\hline $\begin{array}{l}\text { Small } \\
\text { intestine }\end{array}$ & $702 \pm 112$ & $932^{*} \pm 280$ & $10 \cdot 0^{*} \pm 1 \cdot 3$ & $1.25 \pm 0.09$ & $0.65 \pm 0.11$ & $49 \pm 7$ & $2.5 \pm 0.9$ \\
\hline & $30 \pm 56$ & $908 \pm 23$ & $14 \cdot 0^{*} \pm 1 \cdot 3$ & $r^{*}+{ }^{\circ}$ & $0.40^{*} \pm 0.07$ & $63^{*} \pm 6$ & $\pm 2 \cdot 0$ \\
\hline on & $0 \pm 150$ & $407 \pm$ & $22.6 \pm 2.4$ & $2.2^{*} \pm 0.38$ & \pm 0.12 & I $10 \pm 22$ & $2 \cdot 2$ \\
\hline
\end{tabular}

* The individual values from which these means were obtained showed significant differences with time after feeding $(P<0.05)$.

As expected, there were indications that in some organs the amount and nature of the contents changed with time after feeding. These are marked with an asterisk in Table I, and an examination of the corresponding scatter diagrams reveals a tendency for the greatest concentrations to be attained more gradually and to occur later in the distal portion of the tract. Where a change with time was noted, the standard deviation 
was reduced by ro-I $5 \%$ when differences between times were eliminated. In Table I the standard deviation is always given without elimination of the effect of time differences.
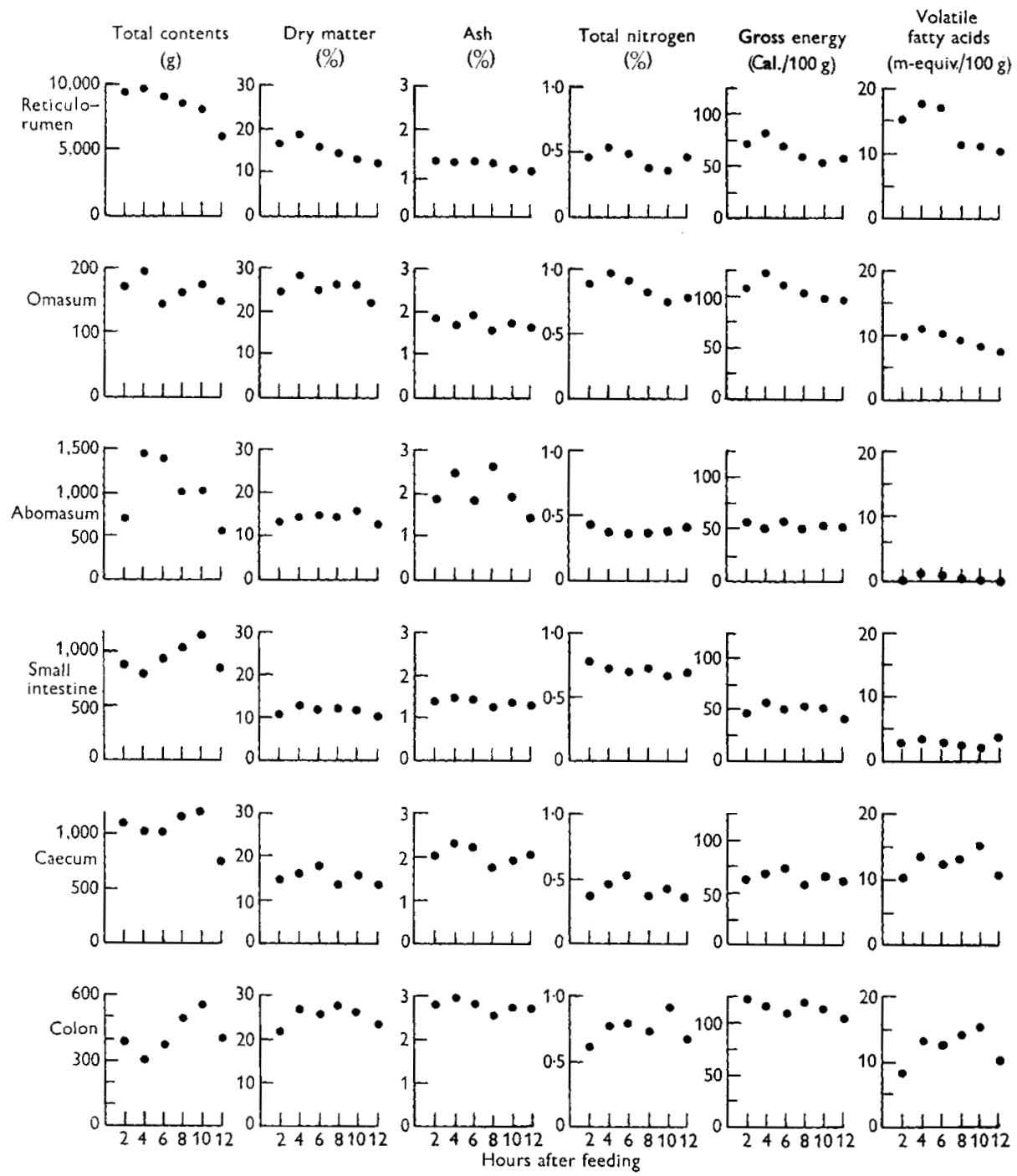

Fig. I. Mean values for total contents and concentration of various constituents along the digestive tract of twenty-one sheep at intervals after feeding.

\section{Changes along the tract}

(I) Approximately two-thirds of the total contents of the tract were contained in the reticulo-rumen. The D.M. in the reticulo-rumen was about $75 \%$ of the total D.M. in the tract just after feeding and fell to about $60 \% \mathrm{I} 2 \mathrm{~h}$ after feeding.

(2) Changes along the tract in concentration of the constituents measured are shown in Table 2, where the concentration of each is expressed as a percentage of its concentration in the reticulo-rumen. 
Vol. Io

As was to be expected, the V.F.A. concentration exhibited a pattern in the sections from reticulo-rumen to colon which was different from that of any of the other constituents measured. The greatest concentrations corresponded to the zones of microbial activity in the rumen and lower intestines.

Table 2. Mean values for concentrations of constituents measured expressed as a percentage of their concentration in the reticulo-rumen of twenty-one sheep

\begin{tabular}{lccccc}
\multicolumn{1}{c}{ Site } & $\begin{array}{c}\text { Dry } \\
\text { matter }\end{array}$ & Ash & Nitrogen & Energy & $\begin{array}{c}\text { Volatile } \\
\text { fatty acids }\end{array}$ \\
Omasum & $\mathbf{1 5 4}$ & $\mathbf{1 4 0}$ & $\mathbf{1 8 8}$ & $\mathbf{1 5 9}$ & 67 \\
Abomasum & 89 & 166 & 85 & 80 & 6 \\
Small intestine & 70 & $\mathbf{1} \mathbf{1 3}$ & $\mathbf{1 5 9}$ & 74 & $\mathbf{2 2}$ \\
Caecum & 99 & $\mathbf{1 6 8}$ & 98 & 95 & 87 \\
Colon & $\mathbf{1 5 9}$ & $\mathbf{2 2 7}$ & $\mathbf{1 6 1}$ & $\mathbf{1 6 7}$ & 86
\end{tabular}

The concentration of V.F.A. in the omasum was about two-thirds of that in the reticulo-rumen, and ten times as great as that in the abomasum. Beyond the abomasum the concentration began to rise again, and in the small intestine was four times that in the abomasum. Values for the two sheep whose small intestines were partitioned indicated that the V.F.A. concentration was higher in the distal than in the proximal portions. In the caecum another fourfold increase brought the concentration almost up to that in the reticulo-rumen. In the colon the concentration was no higher than in the caecum despite the dehydration known to take place in the former.

When the changes in concentration of the other constituents between sections were examined, the following points were noted.

(a) In the omasum the D.M., ash, and energy concentrations were about $50 \%$ higher than in the reticulo-rumen, and the $\mathrm{N}$ concentration about $90 \%$ higher.

(b) In the abomasum the D.M., energy, and $\mathrm{N}$ concentrations were lower than in the omasum, the $\mathrm{N}$ more so than the D.M. and energy, so that they were in the same ratios one to another as they had been in the reticulo-rumen. The ash concentration naturally continued to rise and was about $20 \%$ higher than in the omasum.

(c) The D.M., ash, and energy concentrations were respectively 20,30 and $10 \%$ lower in the small intestine than in the abomasum, whereas the $\mathrm{N}$ concentration increased by some $90 \%$.

Table 3 shows the $\mathrm{N}$ concentrations in terms of total contents, D.M. and organic matter. The increase from abomasum to small intestine in terms of organic matter was, in fact, $140 \%$.

In both sheep in which the small intestine had been divided, the $\mathrm{N}$ concentration was higher in the proximal part. The subsidiary experiment with six sheep was carried out to confirm this finding, and also to see whether the increase in $\mathrm{N}$ concentration in the small intestine could have resulted in part from desquamation, because of damage in expressing the contents. The method of expression had no effect on the $N$ concentration.

The $\mathrm{N}$ and energy concentrations in terms of organic matter, D.M. and insoluble ash are given in Table 4 . It shows that, in contrast to the v.F.A., the concentration of $\mathrm{N}$ 
and energy rose from the abomasum to the proximal part of the small intestine and then fell steadily to the distal portion.

(d) In the caecum the concentrations of D.M., ash, and energy were respectively 40,50 and $30 \%$ greater than in the small intestine, whereas the $\mathrm{N}$ concentration fell by $40 \%$ (Table 2 ).

(e) In the colon the concentrations of D.M., ash, energy and $N$ were higher than in the caecum by $60,35,75$ and $65 \%$ respectively.

Table 3. Mean concentration in different parts of the alimentary tract of twenty-one sheep of total nitrogen and energy, in terms of total contents, dry matter and organic matter

\begin{tabular}{lccc} 
& \multicolumn{2}{c}{ Nitrogen as a percentage of } \\
\cline { 2 - 4 } \multicolumn{1}{c}{ Site } & Contents & $\begin{array}{c}\text { Dry } \\
\text { matter }\end{array}$ & $\begin{array}{c}\text { Organic } \\
\text { matter }\end{array}$ \\
Reticulo-rumen & $0.4 \mathrm{I}$ & 2.7 & 3.0 \\
Omasum & 0.77 & 3.8 & 3.9 \\
Abomasum & 0.35 & 2.8 & 3.2 \\
Small intestine & 0.65 & 6.9 & $7 \cdot 6$ \\
Caecum & 0.40 & 2.8 & 3.1 \\
Colon & 0.66 & 3.0 & 3.3
\end{tabular}

\begin{tabular}{ccc}
\multicolumn{3}{c}{ Energy $(\mathrm{Cal} . / \mathrm{g})$ of } \\
$\begin{array}{c}\text { Dry } \\
\text { matter }\end{array}$ & $\begin{array}{c}\text { Organic } \\
\text { matter }\end{array}$ \\
0.66 & 4.7 & $5 \cdot 1$ \\
1.05 & 4.8 & 5.4 \\
0.53 & 4.5 & 4.5 \\
0.49 & 4.9 & 5.4 \\
0.63 & 4.7 & $5 \cdot 2$ \\
1.10 & 4.7 & $5 \cdot 1$
\end{tabular}

Table 4. Subsidiary experiment to examine contents of reticulo-rumen, abomasum and four segments of the small intestine of six sheep: mean values for ratios of total nitrogen and energy to dry matter, organic matter and insoluble ash

\begin{tabular}{|c|c|c|c|c|c|c|}
\hline \multirow[b]{2}{*}{ Site } & \multicolumn{3}{|c|}{ Ratio of nitrogen to } & \multicolumn{3}{|c|}{ Ratio of energy to } \\
\hline & $\begin{array}{c}\text { Dry } \\
\text { matter } \\
(\%)\end{array}$ & $\begin{array}{c}\text { Organic } \\
\text { matter } \\
(\%)\end{array}$ & $\begin{array}{c}\text { Insoluble } \\
\text { ash } \\
(\mathrm{g} / \mathrm{g})\end{array}$ & $\begin{array}{c}\text { Dry } \\
\text { matter } \\
\text { (Cal./g) }\end{array}$ & $\begin{array}{c}\text { Organic } \\
\text { matter } \\
(\text { Cal } / g)\end{array}$ & $\begin{array}{c}\text { Insoluble } \\
\text { ash } \\
\text { (Cal./0.01 g) }\end{array}$ \\
\hline Reticulo-rumen & $3 \cdot I$ & $3 \cdot 4$ & $1 \cdot 7$ & $4 \cdot 6$ & $5 \cdot 1$ & $2 \cdot 6$ \\
\hline Abomasum & $3 \cdot 5$ & $3 \cdot 9$ & 0.8 & 45 & $5 \cdot 0$ & $I \cdot O$ \\
\hline Small intestine: & & & & & & \\
\hline Proximal segment & $7 \cdot 8$ & $8 \cdot 7$ & $9 \cdot 5$ & $5 \cdot 2$ & $5 \cdot 8$ & $6 \cdot 0$ \\
\hline Second segment & $6 \cdot 4$ & $7 \cdot 2$ & $6 \cdot I$ & $4 \cdot 8$ & $5 \cdot 4$ & $4 \cdot 6$ \\
\hline Third segment & $4 \cdot 8$ & $5 \cdot 5$ & $2 \cdot 9$ & $4 \cdot 6$ & $5 \cdot 3$ & $2 \cdot 8$ \\
\hline Distal segment & $3 \cdot 2$ & $3 \cdot 7$ & $1 \cdot 4$ & $4 \cdot 3$ & $4^{\circ} 9$ & $I \cdot 9$ \\
\hline
\end{tabular}

\section{DISCUSSION}

The feeding system adopted in this experiment corresponded in general to the pattern of indoor feeding of ruminants, and had the advantage that the $12 \mathrm{~h}$ intervals made it possible for the fate of one meal to be studied without the complications of frequent feeding.

According to Gray (I947) about $60 \%$ of the cellulose in the feed is digested in the reticulo-rumen and $30 \%$ in the large intestine. Elsden et al. (1946) have suggested that the greater part of the fatty acids in solution in the liquid portion of material received from the reticulum is absorbed from the omasum: Barcroft, McAnally \& Phillipson (I944) had already shown that fatty acids are absorbed there. From Table I 
and Fig. $x$ it would seem most probable that almost all the v.F.A. produced by microbial digestion has been absorbed before the digesta pass on to the abomasum. It may, in fact, be due to intensive absorption in the omasum that we obtain an enhanced $\mathrm{N}$ concentration there, although it is difficult to see why it should fall back in line with the D.M. and energy concentration in the abomasum.

The concentration of D.M., ash, N, and energy were all increased in the omasum. This finding might be explained by intensive absorption of water as suggested by Gray, Pilgrim \& Weller (1954) or by the preferential passage of liquid digesta on to the abomasum, a thesis supported by the radiographic observations of our colleagues $\mathrm{Mr}$ D. Benzie and Dr A. T. Phillipson (unpublished results) although neither mechanism necessarily excludes the other. An unexpected feature of the omasum in the present experiment was the enhanced $\mathrm{N}$ concentration compared with that of the other constituents, especially when it is seen that in the abomasum they were again in the same ratios one to another as they had been in the reticulo-rumen. This rise in $\mathrm{N}$ concentration in the omasum and subsequent fall in the abomasum may have been caused by the experimental procedures, including character of feed, and may not be of general application. Raynaud (1955) found that, in terms of the D.M., N concentration rose through the omasum to the abomasum of cattle. His material, however, was from slaughterhouse animals which had been starved for $24 \mathrm{~h}$ before killing.

In the present experiments the decorticated groundnut cake and the ground maize in the diet would act as substrates for the rapid production of v.F.A. and undoubtedly account for the rise $2 \mathrm{~h}$ after feeding. Lactic acid would probably also be formed in considerable quantity but was not estimated. V.F.A. formed subsequently would presumably result from digestion of cellulose.

It is generally agreed that there is a steady interchange of material between the rumen and reticulum, with intermittent passage of digesta to the omasum, where dehydration takes place. Our results indicate that this dehydration involves the loss of some $43 \%$ of the moisture content of the digesta, a figure in agreement with that of Gray et al. (1954).

The flow of gastric juice would presumably cause a reduction in D.M., energy and $\mathrm{N}$ concentration in the liquid digesta passing into the abomasum. The chloride of this secretion would be the main reason for the rise in ash concentration.

The considerable rise in the v.F.A. concentration in the distal part of the small intestine is in accordance with comparative studies on the distribution of microorganisms, which indicate an extension orally from the ileocaecal junction but in diminishing numbers. From our knowledge of the caecum the level of this intestinal microbial activity would presumably reach its maximum in that organ and certainly here was found a fourfold increase over the small intestine, bringing the concentration almost up to that in the rumen. The caecum is seen to be an important site of v.F.A. production and the level of activity found in our experiment was of the same order as that found by Elsden et al. (1946) in their sheep no. 4 which was on a diet similar to ours.

The outstanding feature in the small intestine was the considerable increase in the concentration of $\mathrm{N}$, which was greatest at the proximal end and diminished distally. 
This increase might also account for the rise in energy content of the organic matter as shown in Tables 3 and 4. During the course of this work Raynaud (r955) published a similar observation made in cattle starved for about $24 \mathrm{~h}$. The mean values in $\mathrm{g} \mathrm{N} / 100 \mathrm{~g}$ D.M. which he obtained were: rumen $\mathrm{I} \cdot 705$, omasum $2 \cdot 100$, abomasum 2.404 , duodenum 3.479 . It will be noted that here too the concentration in the omasum was higher than in the rumen but that in the duodenum it was about $45 \%$ higher than in the abomasum. Raynaud suggested that the rising proportion of $\mathrm{N}$ depended partly on a relatively faster absorption of the non-nitrogenous constituents and partly on the addition of $\mathrm{N}$ from secretions or desquamated epithelium. We found in our subsidiary experiment with six sheep that the ratio of total $\mathrm{N}$ to insoluble ash had greatly increased between the abomasum and the proximal portion of the small intestine. This segment included the duodenum with its glands and the inflow of bile and pancreatic secretions. The increase in the ratio could not be explained by a relatively greater rate of absorption of the products of carbohydrate digestion, but must have been due mainly to the addition of nitrogenous material into this segment. Preliminary investigations of the combined bile and pancreatic secretions to the small intestine did not indicate that they could account for the bulk of the increase in $\mathrm{N}$ but further investigation of this point is planned. That the succus entericus can add considerable quantities of $\mathrm{N}$ to the digesta has been shown by Mosenthal (IgIr) who found in the dog that $35 \%$ of the $\mathrm{N}$ of the digesta came from this source.

Our results for the caecum indicated a measure of concentration of D.M., energy and ash, and an absorption of $\mathrm{N}$ (possibly as ammonia). Further concentrations in D.M. and ash took place in the colon. There were differences here between the different constituents. The V.F.A. concentration did not increase, suggesting absorption of V.F.A.; the ash concentration did not rise to the same extent as that of N, D.M., or energy, possibly owing to reabsorption of chlorides and other ions.

\section{SUMMARY}

I. Twenty-four Cheviot sheep fed at r2-hourly intervals on equal meals of hay and concentrates were killed at intervals after feeding but three had to be discarded because of feeding irregularities. The alimentary tracts of the remaining twenty-one were separated into their constituent parts: reticulo-rumen, omasum, abomasum, small intestine, caecum and colon. The contents of each part were weighed and analysed for dry matter, ash, total nitrogen, energy and volatile fatty acids. In a subsidiary experiment on six sheep the small intestine was divided into four equal parts.

2. Approximately two-thirds of the total contents of the tract were contained in the reticulo-rumen. The D.M. in this organ fell from $75 \%$ of the total in the tract just after feeding to about $60 \% 12 \mathrm{~h}$ after feeding.

3. The highest values for the substances estimated tended to occur later after feeding and to be attained more gradually in the distal portions of the tract.

4. The greatest concentration of V.F.A. corresponded to the main seats of microbial activity, namely, the reticulo-rumen and the lower part of the small intestine, caecum and colon. The V.F.A. produced in the reticulo-rumen appeared to be almost completely absorbed by the time the digesta reached the abomasum. 
5. In the omasum the D.M., ash and energy concentrations of the contents were about $50 \%$ higher than in the reticulo-rumen and the $\mathrm{N}$ concentration was about $90 \%$ higher.

6. In the small intestine the D.M., ash and energy concentrations of the contents were respectively 20,30 , and 10\% higher than in the abomasum, but the $\mathrm{N}$ concentration was increased by some $90 \%$. It was found that this marked increase in $\mathrm{N}$ concentration in the small intestine was maximal in the first part of its length and fell off distally. This rise was due primarily to a considerable addition of nitrogenous material to the small intestine in its proximal part and not to a relatively faster absorption of non-nitrogenous constituents there. If the addition were mainly of protein then it would account for the parallel rise in calorie value of the organic D.M.

7. In the caecal contents the concentrations of D.M., ash and energy were respectively 40,50 and $30 \%$ greater than in the small intestine, whereas the $\mathrm{N}$ fell by $40 \%$ presumably owing to absorption of ammonia.

8. In the colon the concentrations of D.M., ash, energy and $\mathrm{N}$ were higher than in the caecum by $60,35,75$ and $65 \%$ respectively, presumably largely owing to the absorption of water and salts.

We wish to thank our colleagues Dr A. T. Phillipson and Mr D. Benzie for helpful discussions, and Dr J. Duckworth for making the animals available to us. We are also indebted to $\mathrm{Mr} \mathrm{A}$. Dalgarno for his assistance.

\section{REFERENCES}

Barcroft, J., McAnally, R. A. \& Phillipson, A. T. (1944). F. exp. Biol. 20, 120.

Elsden, S. R., Hitchcock, M. W. S., Marshall, R. A. \& Phillipson, A. T. (1946). 7. exp. Biol. 22 , I91. Gray, F. V. (1947). F. exp. Biol. 24, 15.

Gray, F. V., Pilgrim, A. F. \& Weller, R. A. (1954). J. exp. Biol. 31, 49.

Hale, E. B., Duncan, C. W. \& Huffman, C. F. (r947a). F. Nutr. 34, 737.

Hale, E. B., Duncan, C. W. \& Huffman, C. F. (1947 b). $\mathcal{~}$. Nutr. 34, 747.

Minister of Agriculture and Fisheries and Department of Agriculture for Scotland (1932). S.R. and O. no. 658 .

Mosenthal, H. O. ( (9 г I). F. exp. Med. r3, 3 г9.

Raynaud, P. (I955). Arch. Sci. physiol. 9, 35.

Note added 2 August 1956. Since this paper was written Mr A. M. Badawy, working at this Institute, has found that the $\mathrm{N}$ : lignin ratio of the contents of the alimentary tract of sheep on the same dietary régime confirms this marked addition of nitrogenous material to the contents of the small intestine in its proximal part (unpublished result). 